\title{
Molecular prognostication and lung cancer: Are we cluttering the issue with facts?
}

\author{
Sudish C. Murthy, MD, PhD
}

\footnotetext{
From the Department of Thoracic and Cardiovascular Surgery, Heart and Vascular Institute, Cleveland Clinic, Cleveland, Ohio.

Supported in part by the Daniel and Karen Lee Endowed Chair in Thoracic Surgery, held by S.C.M

Disclosures: Author has nothing to disclose with regard to commercial support.

Received for publication July 27, 2015; accepted for publication July 27, 2015; available ahead of print Aug 29, 2015.

Address for reprints: Sudish C. Murthy, MD, PhD, Department of Thoracic and Cardiovascular Surgery, Cleveland Clinic, 9500 Euclid Ave, Desk J4-1, Cleveland, OH 44195 (E-mail: murthys1@ ccf.org).

J Thorac Cardiovasc Surg 2015;150:993-4

$0022-5223 / \$ 36.00$

Copyright (C) 2015 Published by Elsevier Inc. on behalf of The American Association for Thoracic Surgery http://dx.doi.org/10.1016/j.jtcvs.2015.07.083
}

The comparatively poor survival of patients with early-stage non-small cell lung cancer (NSCLC) remains disappointing and frustrating for patients and clinicians alike. Why should it be that patients with stage I breast cancer have a 5-year survival greater than $95 \%$, whereas those patients with equivalently staged NSCLC would, at best, be expected to have a $20 \%$ to $30 \%$ shorter lifespan? After all, most lung and breast cancers are of similar origin (glandular), and the TNM staging system is used identically for both. What is so different about early-stage NSCLC that even when it is meticulously staged and surgically treated, we are ecstatic to see just 4 of 5 patients with node-negative, completely resected disease actually cured ? $^{1}$ Throw in just a single resected micrometastatic lymphatic implant, and the whole house of cards comes tumbling down with regard to even this tepid survival expectation. What are we missing? What is this fog of war that so thoroughly shrouds the survival of patients with NSCLC? Clearly, early-stage NSCLC is a very heterogeneous disease.

We have looked at cancer size, shape, and differentiation; at lymphovascular invasion; at histopathologic subtype; and at essentially anything else you can imagine viewing through a light microscope as possible risks that stratify survival, and have done so for years. Yet our survival models remain relatively unchanged, despite the road being littered with literally hundreds of seemingly well-designed and thoughtfully conceived studies aimed at clarifying these muddied waters.

Now, Pio and colleagues ${ }^{2}$ have stepped up to the plate and offer us another promising analytic tool. Molecular analyses of one form or another have crept into mainstream cancer diagnostics during the past few decades and are becoming progressively refined and sophisticated. Refinement in this sense should not be confused with complexity, for although the science is indeed becoming more complex, clinical application is becoming more simplistic and, ultimately, easier to disseminate. now.

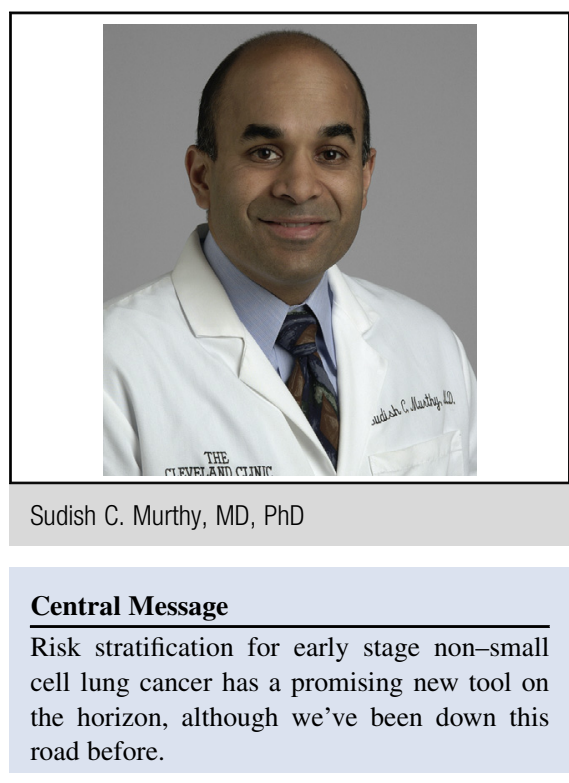

See Article page 986.

As with most other solid organ cancers, unlocking a molecular signature of NSCLC in hopes of better predicting survival began with the low-hanging fruit of oncogene expression, tumor suppressor gene function, and classic mitotic pathway regulators. Early findings were interesting, but generally fell into the "so what?" category. We have stockpiled billions of bytes of expression array data and spent our intellectual capital on understanding sophisticated mosaics of gene expression that are only fair predictors of survival. Although this has made for a few decent academic careers and probably some well-funded grant proposals, transformative translation data are lacking — until perhaps

Pio and colleagues ${ }^{2}$ have set their sights on more obscure targets, perhaps recognizing that the path less traveled might lead to the prize. Who would have suspected that the expression of RNA metabolism-related genes might be a key to solving this puzzle? Apparently, these scholars did. They have devised a simple 5-gene expression signature that they demonstrate is able to dichotomize patients with resected early-stage lung cancers into high- and lowrisk populations for recurrence. Depending on which data set they validate against, low-risk 5-year survival is above $80 \%$ and even as high as $100 \%$.

As with most studies, there is an urge to add more data, and in this case, Pio and colleagues ${ }^{2}$ detract from their 
bottom-line results by including squamous cancers rather than restricting their focus to adenocarcinoma. Nonetheless, the take-home message is strong, and something that our medical oncology colleagues have been seeking for 3 to 4 decades. The risk stratification allows Pio and colleagues ${ }^{2}$ to identify which individual patients with early NSCLC are the best candidates for adjuvant therapy and conversely, which might be potentially discharged from the practice needing little to no surveillance (and no additional treatment) and pronounced cured!

The one thing that remains lacking, however, is an understanding of how this latest "new and improved" analytic compares with all those that have come before. There are, of course, other expression arrays that have been generated, other focal mutations that have been identified, and other proteonomic signatures that have previously been heralded. How does this 5-gene assessment stack up against these other? Perhaps more importantly, in light of cost constraints going forward (and I suspect it is highly unlikely that this intellectual property will be freely distributed), how might this novel intervention stack up against the honorable light microscope? Is it better than degree of differentiation, lymphovascular invasion, or adenocarcinoma subtyping?

There is little doubt that this is an exciting and promising development in NSCLC survival prediction that might help clinicians identify the early cancers that behave like early breast cancers and, more importantly, those that don't. But the track record for these types of studies is surprisingly poor, and we often end up simply cluttering the issue with facts and adding to the ever increasing amount of white noise of NSCLC. Let's hope that this is not the case here.

\section{References}

1. Murthy SC, Reznik SI, Ogwudu UC, Farver CF, Arrossi A, Batizy LH, et al. Winning the battle, losing the war: the noncurative "curative" resection for stage I adenocarcinoma of the lung. Ann Thorac Surg. 2010;90:1067-74.

2. Pio R, Agorreta J, Montuenga LM. Prognostic signature of early lung adenocarcinoma based on the expression of ribonucleic acid metabolism-related genes. J Thorac Cardiovasc Surg. 2015;150:986-92. e1-11. 